\title{
THE USAGE OF MOBILE APPLICATION TO TEACH PRACTICAL SKILLS AMONG CATERING STUDENTS
}

\author{
Adibah Aishah Md Sahak ${ }^{1}$, Melor Md Yunus², Abdul Wafi Abdul Rahman², \\ Hairuddin Harun ${ }^{4}$, Marwanti ${ }^{5}$, and Nor Anis Intan Aqiah Tukiran ${ }^{6}$ \\ ${ }^{1346}$ Fakulti Pendidikan Teknikal dan Vokasional, Universitas Tun Hussein Onn Malaysia, Malaysia \\ ${ }^{2}$ Fakulti Pendidikan, Universiti Kebangsaan Malaysia, Malaysia \\ ${ }^{5}$ Faculty of Engineering, Universitas Negeri Yogyakarta, Indonesia \\ Email:adibah@uthm.edu.my
}

\begin{abstract}
Latest educational media based on mobile application nowadays is an important tool for teaching and learning which can help to attract the students' attention and the students will be more efficient since they can study on their own anywhere and anytime with different situations surround them. This paper focuses on the usage of the mobile application in teaching practical skills among catering students. In line with the issues nowadays where the live demonstration is too backdated rather than using the mobile application to enhance the enjoyment of the cooking process in catering classroom. Teaching and learning with the mobile application was perceived to assist the learning process in cooking by following ways: increasing the comprehension of the cooking process and real-time to reassurance in the cooking process, enhancing the enjoyment of the cooking process and acquire new cooking skills. The findings show that the usage of mobile application is at moderate level. On the other hand, the positive implication towards students is at medium level. Overall, for this study, researchers found that the usage of mobile application among catering students was good and perceived positively towards students.
\end{abstract}

Keywords: catering, mobile application, practical skills, teaching, and learning

\section{INTRODUCTION}

The integration of educational technologies will continue to change the nature of education. Aligned with that, $7^{\text {th }}$ Key Focus Area of Education Development Plan of Malaysia (KPM) has outlined utilizing ICT to improve quality of learning, which is the use of technology are important tools for all generation to sustain the quality of teaching and learning (PPPM, 20132025). Despite that, Ministry of higher education (MOHE) also has outlined learning online globally in the $8^{\text {th }}$ Key Focus Area (Higher Education Development Plan Malaysia 2013-2025) as an effort in utilizing ICT to upgrade the education in Malaysia is comparable to world advanced countries. Mobile application is a part of ICT. The development of mobile application in the age of globalization is now demanding education to make changes and adapts to remain relevant in terms of preparation and human capital development to the nation. The mobile application becomes a necessity in education and needs to be utilized entirely by educators to produce informative communities as well as global-minded.

The mobile application such as YouTube, Instagram, Facebook, Sketchbook, Padlet, Mooc, Sparkol, and Plotagon can be greatly utilized toward Gen $\mathrm{Z}$ because this generation is comfortable with the internet since at the young age. All of them are recently interacting through social media, online video and smartphones. Obviously, this generation looks at a different perspective on the relationship between cooking, technology, and education. 
In line with the issue nowadays, the live demonstration is too backdated rather than using the mobile application to enhance the enjoyment of the cooking process in catering classroom. The students tend to feel bored and no more interested to learn about the cooking processes by using the recipe cards only which can be categorized as the traditional way and method of teaching in the cooking class. Using a mobile application to stream videos and images allow the lessons to be taught and reviewed multiple of times without depending too much with the instructor. These statements are aligned with Wishart [1] where the visualization is an important key in understanding the key concepts and methods of cooking. In addition, the skills of cooking may also be instilled and enhanced by the students via the real videos and images streamed by them from the mobile applications available nowadays. The results emphasize the visual nature of video as a beneficial learning tools.

Watching the streaming video over and over again is akin to learn by students' own initiative in which streaming live videos, with a qualified lecturer to monitor and observe the right channels to be referred by the students to learn about the skills being taught is a possible solution and will produced a better results at the end.

\section{METHOD}

The aim of this study is to investigate the usage of the mobile applications among catering students in the practical skills. This study can be interpreted using both quantitative and qualitative approaches through the sectional study that considered the most appropriate methods. The researchers conduct this study in one of the Technical and Vocational Education
University in Batu Pahat (UTHM). The number of students in the Catering department, there in total of 190 students in catering, based on the information given by the Admission and Registry Department of Technical and Vocational.

Krejcie \& Morgans [2], determining that sample size of 127 students with total population of 190 students is sufficient to collect the data. The instrumentation of this study is using a five-point Likert scale. Other than that, the scale in the Likert scale refers to the total sum of all Likert items in the questions. This study also used an interval scale. Value of 1 refers to (strongly disagree) the most disagree attitude in the scale, 2 (disagree), 3 (neutral), 4 (agree) and 5 (strongly agree) the most strongly attitude in the scale. The information in the questionnaires provide details about the researcher and the purpose of the survey.

The survey aims to identify the usage of mobile application among catering students and the positive implications and benefits towards students to gain a piece of knowledge and skills by using the mobile application. In the questionnaires also stated the responses will be confidential, the response to all the questions as completely and accurately, no right or wrong answer and also the response should truly be aligned with the student's opinion. In addition, there will be positive feedbacks on the completion of the questionnaire. About 127 respondents completed the questionnaire which was collected with the good responses.

The data coded for analysis using a Statistical Package of Social Science (SPSS), Version 20. Analysis of variance (ANOVA) used to explain the interaction effect the use of mobile application in teaching practical skills among catering students also the positive implication and benefits the students gained after through the 
mobile application during the process of learning. Pallant [3] suggested that the idea Cronbach's alpha coefficient of a scale should be above .70 to indicate high internal consistency. Hinton [4] suggested that an alpha score in the range of .50 to .70 is commonly accepted and considered to be the criterion for demonstrating the internal consistency of a reliable scale. Based on Hair et al. [5] the reliability test can also be interpreted according to the strength using the rules of thumb.

\section{RESULTS AND DISCUSSION}

The research objectives are (1) to identify the usage of mobile application among catering students, (2) to identify the positive implications and benefits the students gained after using the mobile application. The research questions includes (1) What are the importance of using mobile applications as a learning method toward catering students? and (2) What are the positive implications and benefits gained by using the mobile application in teaching and learning toward catering students?

The overall analysis of the average mean score and standard deviation is presented in Table 1. The expected result of this study is similar with past research by Surgenor, et al. [6]. The result of this study proved that majority of the responses from the students was positively perceived the mobile application such as video technology. The mobile application focused on video technology was improved their technical skills required in the cooking process, for example, Béchamel Sauce making and Bolognese making, while the results show that viewing the full video before task plus recipe card and viewing each segment then cook plus recipe card make student recall all of its contents and they retained specific images key stages of the cooking steps.

Table 1. Overall Analyses of Average Mean Score and Standard Deviation

\begin{tabular}{lcc}
\hline \multicolumn{1}{c}{ Aspect } & Mean & $\begin{array}{c}\text { Standard } \\
\text { deviation }\end{array}$ \\
\hline $\begin{array}{l}\text { The use of mobile } \\
\text { application among catering } \\
\text { students }\end{array}$ & 3.50 & 0.376 \\
$\begin{array}{l}\text { The positive } \\
\text { implication and } \\
\text { benefits the students gained } \\
\text { after using the mobile } \\
\text { application }\end{array}$ & 3.44 & 0.432 \\
\end{tabular}

From the observation made by the lecturer, it shows that the students are very eager to dig the knowledge and learn faster by using the YouTube and video applications in smartphone especially when the learning processes start with streaming the videos in the smartphone. Mobile technology devices provide interactive, media-rich, and exciting new environment for the students [7].

The prediction answer for the second research question based on previous research is related to the cooking methods by mobile application through the video. It highlights the significance of visualization in the development of the cooking skills is existed. Besides that, students did consider watching the demonstration prior to begin the cooking beneficial for anticipating that certain stages within the cooking processes are being completed correctly.

Other than that, the positive implication gained by using mobile application in teaching and learning toward catering students occurred when the students viewing step by step sequencing of video indirectly reduced the need to recall aspects of the recipe as they simply followed the video real-time [6] and also helped students to prevent cognitive overload [8]. 
One of the positive implications side and benefits for the students gained after using the mobile application is the students will be integrated with the mobile application through the videos into the classroom or kitchen which will give potential for them to be facilitated with a more collaborative approach to the catering education. Students could know how to download recipes between each other and work in a collaborative manner. By using two media of learnings, recipe cards and videos can improve their ability to think and communicate during the learning session. Even so, collaborative learning using the mobile application must be facilitated and supported in an adequate manner by the teacher [9] or in this case the catering lecturer.

Other than that, one of the important activities during the teaching processes, streaming video from mobile application in practical skills, in which according to Strom [10], is a low resource, cost-effective and easily delivered manner instruction. Students and educators always use this method to add-on their current knowledge. Streaming video allows for movement images to be downloaded or streaming in a smartphone. In most instances, there is no sound attached to the videos or images. The streaming video can be repeated in a loop, constantly played, or upon demand.

The catering classroom or kitchen technologies in teaching and learning changes and innovation are the reality proven and shown which can be seen by the real ayes nowadays. Educators must have the knowledge about the technology to be used in the teaching and learning in the different aspects to motivate students. As with educators, aspiring catering students must be aware of current technological advancements in order to remain competitive and current [11].

\section{CONCLUSION}

This study shows that the usage of mobile application is at moderate level. The positive implication towards students is at medium level. Overall, for this study, the findings indicate that the usage of mobile application among catering students was good and perceived positively towards students. Although the finding shows a moderate level of students usage of the mobile applications from the two objectives, neither faculty nor the university needs to further enhance this method so that it can be applied by the entire staff in the teaching and learning processes and procedures.

\section{REFERENCE}

[1] J. Wishart, "Using the Cameras On Mobile Phones, Ipads and Digitals Cameras to Create Animations in Science Teaching and Learning Mobile Learning and STEM," Case Stud. Pract., vol. 17, no. 1, pp. 18 26, 2016.

[2] R. V. Krejcie and D. W. Morgan, "Determining Sample Size for Research Activities," Educ. Psychol. Meas., vol. 30, no. 607-610, 1970.

[3] J. Pallant, A Step by Step Guide to Data Analysis Using SPSS (4th Edition). Crows Nest: Allen \& Unwin, 2011.

[4] P. R. Hinton, Statistics Explained, 2nd Editio. London: Routledge, 2004.

[5] J. F. Hair, A. H. Money, P. Samouel, and M. Page, Research Methods for Business. West Sussex: John Wiley and Sons Limited, 2007.

[6] D. Surgenor et al., "The Impact of Video Technology on Learning: A Cooking Skills Experiment. 
Appetite," Appetite, vol. 114, pp. 306-312, 2017.

[7] H. Montrieux, R. Vanderlinde, T. Schellens, and L. De Marez, "A Qualitative Explorative Study about the Introduction of Tablet Devices in Secondary Education," PLoS One, vol. 10, no. 12, 2015.

[8] R. E. Mayer and R. Moreno, "Nine Ways to Reduce Cognitive Load in Multimedia Learning," Educ. Psychol., vol. 38, no. 1, pp. 43-52, 2003.
[9] M. Volman and E. Van Eck, "Gender Equity and Information in Technology: The Second Decade," Rev. Educ. Res., vol. 71, no. 4, pp. 613-634, 2001.

[10] J. Strom, Streaming Video: Overcoming Barriers to Teaching and Learning. Manchester: University of Manchester, Advanced Telematics Centre, 2002.

[11] N. Cullen, The World of Culinary Supervision, Training and Management. New Jersey: Prentice Hall, 2000. 